\title{
Progesterone prevents development of neuropathic pain in a rat model: Timing and duration of treatment are critical
}

This article was published in the following Dove Press journal:

Journal of Pain Research

4 April 20II

Number of times this article has been viewed

\author{
Liliane J Dableh \\ James L Henry \\ Department of Psychiatry \\ and Behavioural Neurosciences, \\ McMaster University, Hamilton, \\ Ontario, Canada
}

Correspondence: James L Henry Department of Psychiatry and Behavioural Neurosciences, McMaster University, Health Sciences Centre, Room 4N35, 1200 Main Street West, Hamilton, Ontario L8N 3Z5, Canada Tel + I 9055259 I 40 ext 2775 I Fax + I 9055228844 Email jhenry@mcmaster.ca
Background: Progesterone is emerging as an important protective agent against various injuries to the nervous system. Neuroprotective and remyelinating effects have been documented for this neurosteroid, which is synthesized by, and acts on, the central and peripheral nervous systems. Neuropathic pain is a severe, persistent condition that is generally resistant to treatment, and poses major personal, social, and economic burdens. The purpose of this study was to determine if single-dose or repeated progesterone administration would alleviate tactile hypersensitivity in a rat model of neuropathic pain, and to determine if early versus late initiation of treatment has an effect on the outcome.

Methods: Rats were unilaterally implanted with a polyethylene cuff around the sciatic nerve, and sensitivity to von Frey filament stimulation was measured over approximately 12 weeks.

Results: Rats given progesterone starting one hour after cuff implantation, and daily until day 4, exhibited tactile hypersensitivity similar to that of vehicle-treated rats for the duration of the study. When progesterone was started one hour after cuff implantation and given daily until day 10, rats exhibited no tactile hypersensitivity in the later part of the study, after treatment had stopped. When progesterone treatment was initiated at 20 days, once the model had been fully established, and given daily for 4 or even 11 days, no differences in withdrawal thresholds were observed compared with controls. Progesterone did not have any effect on withdrawal thresholds when given as a single dose, as measured at 30, 60 and 90 minutes after administration.

Conclusion: These results indicate that progesterone, when administered immediately after nerve injury, and for a sufficient period of time, can prevent the development of neuropathic pain, and may offer new strategies for the treatment of this highly debilitating condition.

Keywords: progesterone, neurosteroid, neuropathic pain, peripheral neuropathy, recovery, neuroprotection

\section{Introduction}

Neuropathic pain is a chronic, debilitating condition that results from various injuries and diseases of the central and peripheral nervous systems, and has been described as a neurodegenerative disease. ${ }^{1,2}$ Such insults to the nervous system may include, but are not limited to, nerve trauma, amputation, nerve compression or entrapment, diabetes, stroke, demyelinating disorders, nerve tumors, viral infections, and chemotherapy. Current pooled estimates of the incidence of neuropathic pain suggest that it affects $3 \%$ of the population. ${ }^{3}$ Although heterogeneous in origin, the experience of neuropathic pain is described in similar terms, such as burning, shock-like, pricking, tingling, or cold. ${ }^{4}$ It is often severe and unrelenting, and is generally undertreated with the pharmacological and surgical interventions that are presently available. ${ }^{5}$ Neuropathic pain, therefore, has a profound negative impact on the life of the sufferer and poses an 
economic burden due to high health care costs and disability. ${ }^{6}$ The undertreatment of this devastating condition indicates that new and effective evidence-based treatment options are urgently needed.

It has been shown that progesterone reduces neuronal damage and improves functional outcome in animal models of traumatic brain injury. Following frontal aspiration lesion, pseudopregnant female rats showed less impairment in spatial learning than did normally cycling females, ${ }^{7}$ and virtually no edema after contusion injury to the medial frontal cortex. ${ }^{8}$ Further investigation showed that progesterone was the critical factor in reducing edema. ${ }^{8}$ Treatment with progesterone after contusion injury also decreases edema, ${ }^{9}$ improves Morris water maze performance, and reduces secondary neuronal loss. ${ }^{10}$

Progesterone has been reported to have neuroprotective effects in animal models of several other types of neurological disorders. In a rat model of stroke, where the middle cerebral artery was occluded, treatment with progesterone decreased cerebral infarct volume, edema, inflammation, neuronal death, and increased neurological function. ${ }^{1-16}$ Neuroprotective effects were also observed with progesterone administration in models of spinal cord injury, ${ }^{17,18}$ a genetic model of spinal cord motor neuron degeneration (Wobbler mouse), ${ }^{19}$ and in experimental allergic encephalomyelitis, an animal model of multiple sclerosis, as described by El-Etr et al. ${ }^{20}$ The proposed mechanisms by which progesterone exerts these neuroprotective effects include reduction of edema, oxidative stress, and apoptosis, as well as reduction of inflammation by inhibiting microglial cell activation and production of proinflammatory cytokines. ${ }^{21,22}$

The results of human studies have been consistent with the findings from animal studies. In ProTECT (a randomized controlled trial of experimental clinical treatment with progesterone for acute traumatic brain injury), there was a 50\% lower 30-day mortality rate in subjects receiving progesterone treatment after acute traumatic brain injury compared with those randomized to receive the placebo. The survivors who sustained moderate injury and received progesterone had better outcomes and were less disabled than those with moderate injury receiving the placebo. ${ }^{23}$ A second randomized controlled trial ${ }^{24}$ showed that, after severe traumatic brain injury, the progesterone-treated group had better outcomes at the three- and six-month follow-up, and a lower mortality rate after six months. Two Phase III clinical trials were scheduled to begin in $2010 .{ }^{25}$ Also, there is a decreased relapse rate in women with multiple sclerosis during pregnancy, especially during the third trimester, suggesting a possible protective role for progesterone in multiple sclerosis. ${ }^{26,27}$

Therefore, the rationale for the present study is that because progesterone plays a protective role following nerve injury, it may be effective in alleviating the resulting pain scores in a rat model of peripheral neuropathy. It was hypothesized that chronic progesterone treatment will delay or limit the development of hypersensitivity in a rat model of neuropathic pain. The model used here consists of fitting a $2 \mathrm{~mm}$-long polyethylene cuff around one sciatic nerve of the rat, based on the method described by Mosconi and Kruger. ${ }^{28}$ Hypersensitivity was measured using calibrated von Frey filaments according to the method described by Chaplan et al. ${ }^{29}$ Because common clinical practice indicates that neuroprotective interventions should be performed immediately after injury, it was further hypothesized that early progesterone treatment would be more effective than treatment initiated after pain hypersensitivity has been established. To compare early versus late treatment, rats were given progesterone starting immediately after cuff implantation surgery, and continued daily until day 4 or day 10 , or progesterone was started on day 20 after cuff implantation, and continued daily until day 23 or day 30 . Effects of a single dose of progesterone on hypersensitivity were also tested at 30,60 , and 90 minutes after administration.

\section{Materials and methods}

\section{Animals}

Male Sprague-Dawley rats (Charles River, QC) were housed in pairs and maintained on a 12-hour light cycle, with food and water available ad libitum. All procedures complied with the Guidelines for the Care and Use of Experimental Animals issued by the Canadian Council on Animal Care. All procedures were also approved by the Animal Research Ethics Board (McMaster University, Hamilton, ON). For three days prior to any behavioral testing, the rats were kept in their home cages in the testing room for approximately three hours each day. During this time, rats were intermittently handled by the investigator, and introduced to the testing chamber for a brief period of time (approximately 15 minutes).

\section{Model induction}

The method of sciatic nerve cuffing was based on that described by Mosconi and Kruger. ${ }^{28}$ Rats were anesthetized with a combination of ketamine (Ketalean ${ }^{\circledR} 5 \mathrm{mg} / 100 \mathrm{~g}$; Bimeda-MTC Animal Health Inc, Cambridge, ON), xylazine (Rompun ${ }^{\circledR} 0.5 \mathrm{mg} / 100 \mathrm{~g}$; Bayer HealthCare, Toronto, ON), and acepromazine (Atravet ${ }^{\circledR} 0.1 \mathrm{mg} / 100 \mathrm{~g}$; Ayerst Veterinary 
Laboratories, Guelph, ON) given intraperitoneally. The left sciatic nerve was exposed after blunt dissection of the overlying muscle and freed from the surrounding tissue. A cuff made of a 2-mm segment of polyethylene tubing (Intramedic PE-90; Clay Adams, Division of Becton Dickinson, Parsippany, NJ) slit longitudinally was fitted around the nerve. Subsequently, the muscle was sutured, and the skin closed using suture clips. Antibiotic ointment (Furacin ${ }^{\circledR}$, nitrofurazone $0.2 \%$; Vetoquinol N.-A. Inc, Lavaltrie, QC) was applied over the wound, and $0.03 \mathrm{~mL}$ of antibiotic (Tribrissen ${ }^{\circledR} 24 \%$; trimethoprimsulfadiazine; Schering Canada Inc, Pointe Claire, QC) was injected subcutaneously. Animals were given $1 \mathrm{~mL}$ saline subcutaneously; ocular lubricant, and placed under a heating lamp until they recovered from the anesthetic, and were then returned to their home cages.

\section{Paw withdrawal thresholds}

The testing chamber consisted of a $30 \times 30 \times 30 \mathrm{~cm}$ Plexiglas $^{\circledR}$ box with a clear Plexiglas ${ }^{\circledR}$ floor based on the method described by Pitcher et al. ${ }^{30}$ The floor contained $0.5 \mathrm{~cm}$ diameter holes that were spaced $1.5 \mathrm{~cm}$ apart, and was positioned over a mirror tilted to $45^{\circ}$ which allowed an unobstructed view of the rat paws. Each rat was placed with its cage mate in the testing chamber and allowed to acclimatize for 30 minutes prior to testing. Both rats were in the chamber during testing. von Frey filaments (Stoelting Co, Wood Dale, IL) were applied to the soft tissue of the plantar surface of the hind paw to determine the withdrawal threshold, according to the "up-down method". The first filament applied corresponded to a force of $2 \mathrm{~g}$. Each filament was applied three times, at intervals of three seconds. If a negative response (no movement) was observed, the filament exerting the next greater force was applied. If a positive response (paw withdrawal) was observed, the next filament of lesser force was used next. A 50\% response threshold was calculated according to the response pattern observed, as described by Chaplan et al. ${ }^{29}$ The maximum score possible was $15 \mathrm{~g}$, and the minimum was $0.25 \mathrm{~g}$.

\section{Drug and time of administration}

Progesterone (4-pregnene-3,20-dione; Sigma Chemical Co, St Louis, MO) was given at a dose of $4 \mathrm{mg} / \mathrm{kg}$, dissolved in peanut oil and administered intraperitoneally at a volume of $0.1 \mathrm{~mL} / 100 \mathrm{~g}$ body weight. The progesterone solution was freshly prepared on each day of injection. The structure of the progesterone used was identical to that of progesterone naturally occurring in humans. This dose of progesterone was chosen based on previously published reports showing that this was a relatively low dose that was effective with repeated treatment in other models of nerve injury.,10,31,32 Control group rats were given peanut oil $0.1 \mathrm{~mL} / 100 \mathrm{~g}$ intraperitoneally.

\section{Repeated treatment}

Drug or vehicle was administered in one of two types of regimens, ie, during the onset phase of model development, termed "early treatment", and after the model had fully established, termed "late treatment". These times were chosen to clarify the possible effects of repeated progesterone administration during the onset phase and during the maintenance phase of the model. For the early treatment groups, progesterone was administered starting approximately one hour after cuff implantation surgery, and continued once daily for 4 (PROG d0-4) or 10 (PROG d0-10) additional days. The early vehicle groups were given peanut oil injections according to the same schedule (VEH d0-4 and VEH d0-10).

For the late treatment groups, day 20 was chosen as the start of treatment because our previous studies have indicated that the model is fully established and stable by this time. Progesterone was administered daily on days 20-23 after surgery (PROG d20-23) or on days 20-30 after surgery (PROG d20-30). The late vehicle groups were given peanut oil injections according to the same schedule (VEH d20-23 and VEH d20-30). For repeated treatment, injections were always given after measurement of paw withdrawal thresholds.

\section{Single-dose treatment}

Baseline paw withdrawal thresholds were measured, and rats were injected with the peanut oil vehicle. Withdrawal thresholds were measured again at 30,60, and 90 minutes after injection. The following day, baseline readings were taken, and the rats were injected with progesterone. Withdrawal thresholds were measured at 30, 60, and 90 minutes. Singledose testing was done early (days 3 and 4 ) and late (days 87 and 88) after cuff implantation. For the early treatment group, vehicle was given on day 3 and progesterone on day 4 after cuff implantation. For the late treatment group, vehicle was given on day 87 (to rats previously given progesterone on days 20-30) and progesterone was given on day 88 (to another group of rats previously given vehicle on days 20-30).

\section{Statistical analyses}

For repeated progesterone administration (Figures 1-4), data were analyzed using a repeated measures two-way analysis of variance. A repeated measures one-way analysis 


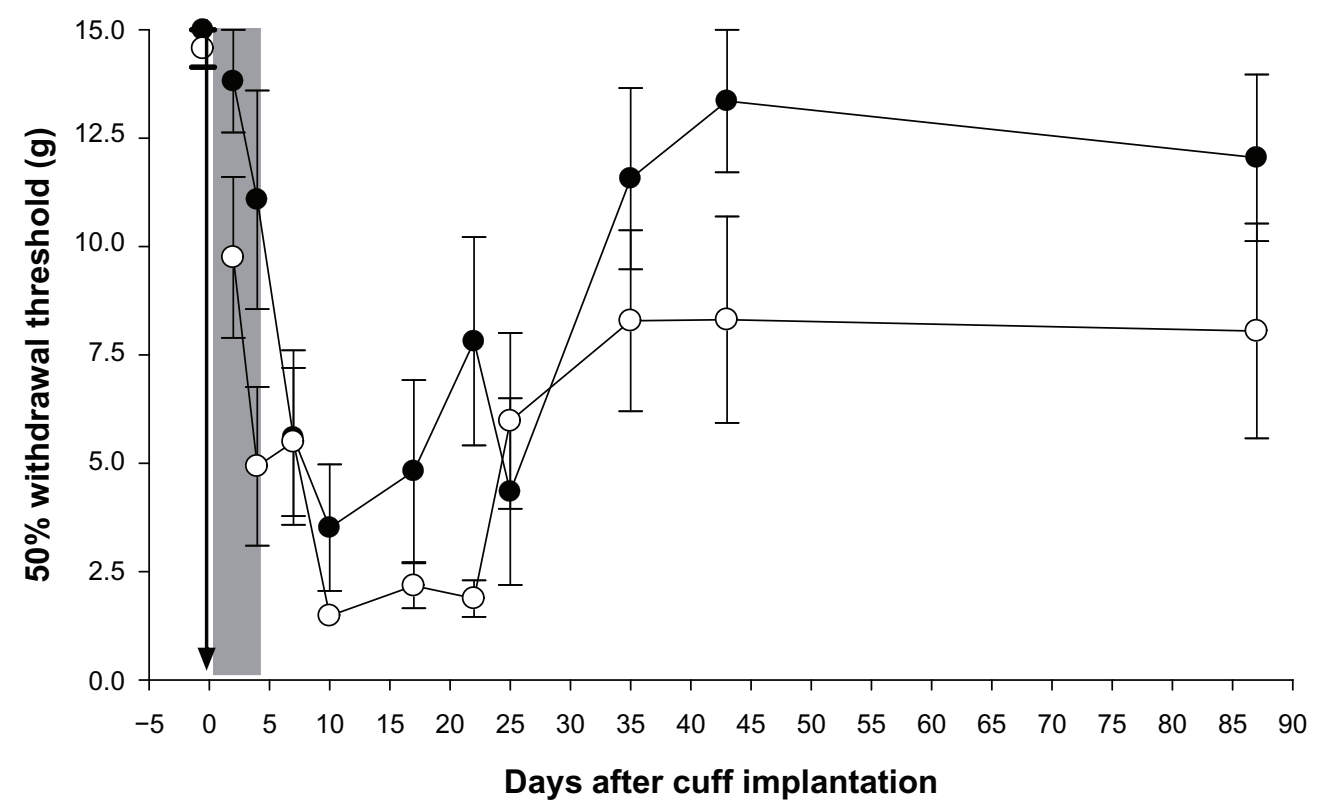

Progesterone (4 mg/kg, intraperitoneal $\mathrm{n}=6$, treatment on days $0-4)$

$-O-$ Vehicle (intraperitoneal $n=7$, days $0-4$ )

Figure I Early treatment on days 0 to 4.

Notes: Withdrawal thresholds of cuff-implanted rats were measured over 87 days to determine the effect of repeated progesterone treatment starting immediately after model induction. Rats were implanted with a sciatic nerve cuff on day 0 and given progesterone $4 \mathrm{mg} / \mathrm{kg}$ intraperitoneally (closed circles; $\mathrm{n}=6$ ) or peanut oil vehicle (open circles; $n=7$ ) starting one hour after surgery, and once daily until day 4 . Arrow denotes time of cuff implantation, and shaded area indicates the days on which injections were given. Data are expressed as means \pm standard error of the mean.

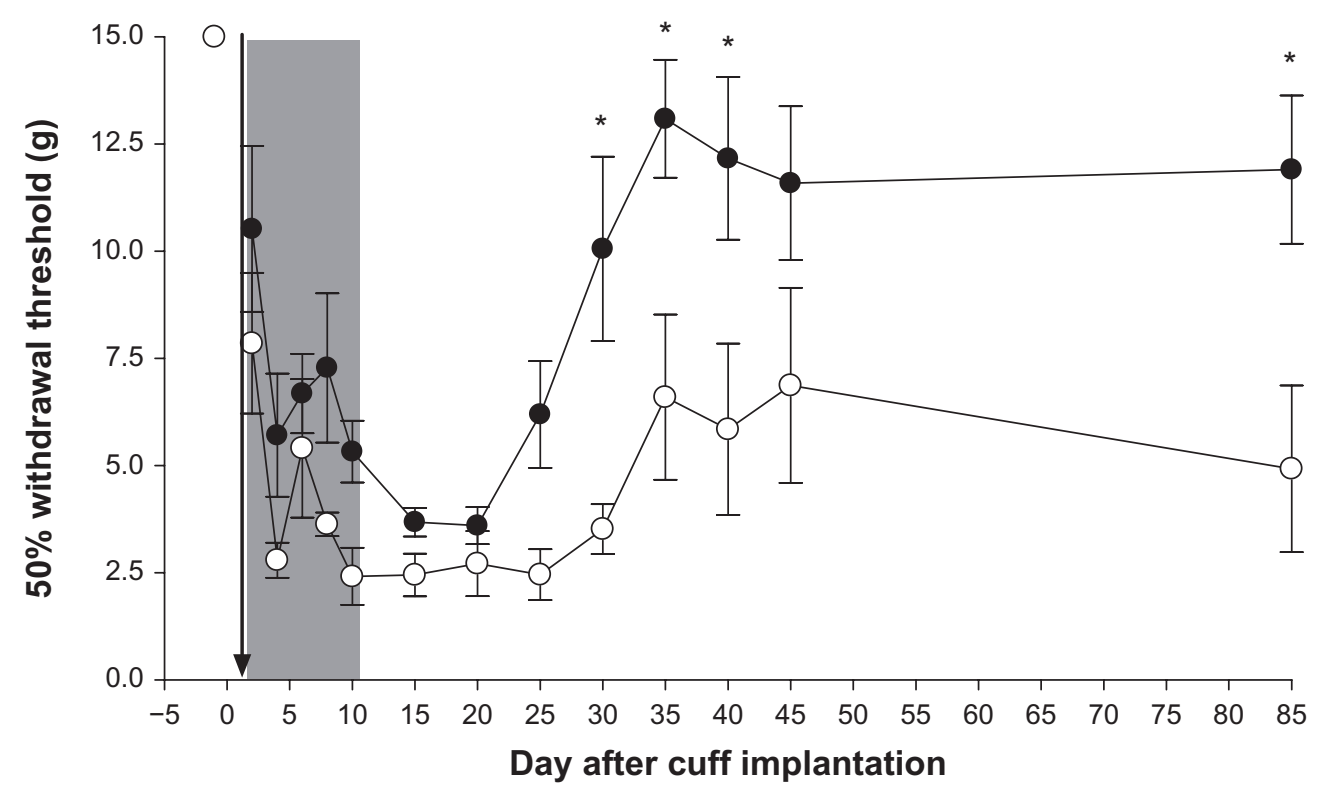

Progesterone (4 mg/kg, i.p., $\mathrm{n}=8$, treatment on days 0-10)

Vehicle (i.p., $n=7$, days $0-10$ )

Figure 2 Early treatment on days 0 to 10.

Notes: Rats were given repeated progesterone treatment $4 \mathrm{mg} / \mathrm{kg}$ intraperitoneally (closed circles; $\mathrm{n}=8$ ) or peanut oil vehicle (open circles; $\mathrm{n}=7$ ) starting one hour after cuff implantation surgery, and once daily until day 10. Rats treated with progesterone on days 0-10 showed significantly higher withdrawal thresholds than vehicle-treated rats on day $30(* P<0.05), 35$ (*P<0.05), $40(* P<0.05)$, and $85(* P<0.05)$. Arrow denotes time of cuff implantation, and shaded area indicates days on which injections were given. Data are expressed as means \pm standard error of the mean. 


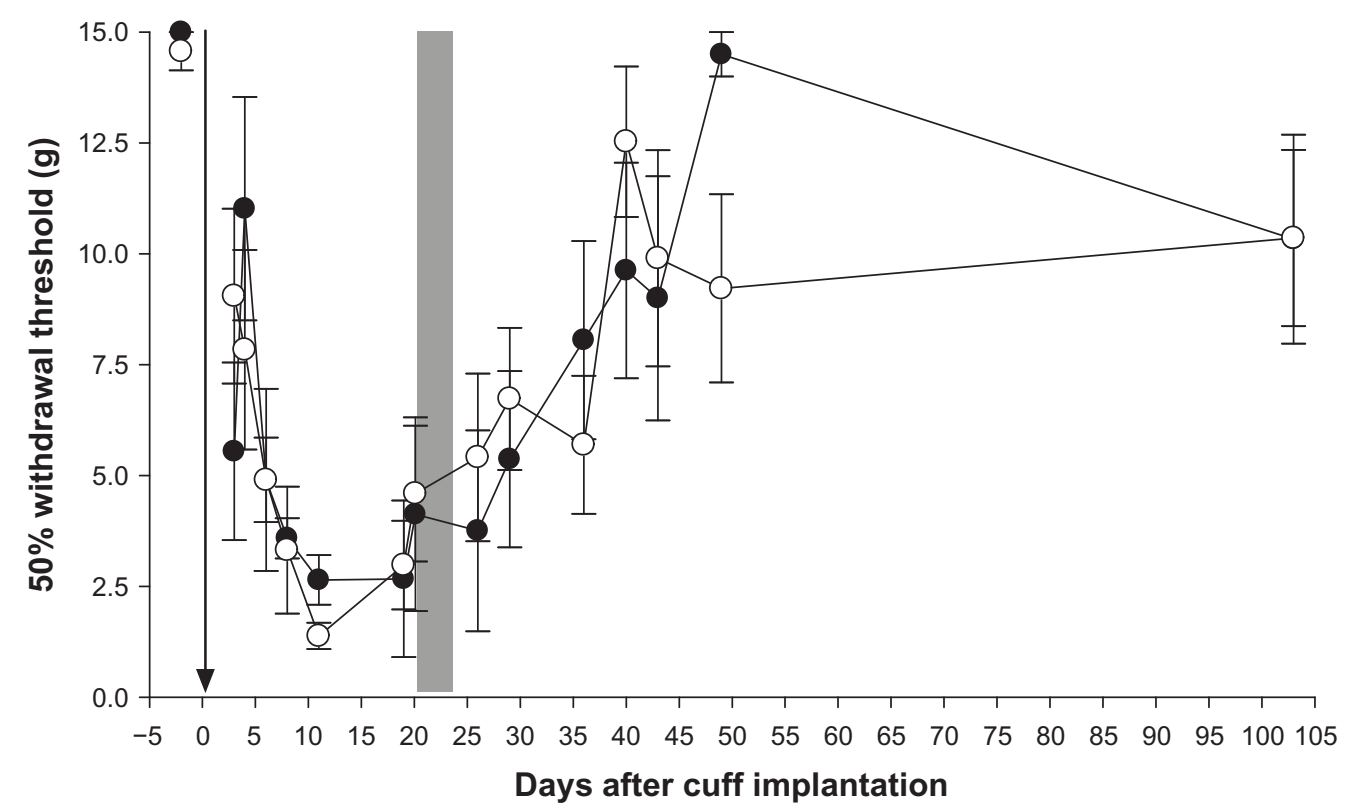

- Progesterone (4 mg/kg, intraperitoneal $\mathrm{n}=6$, treatment on days 20-23)

$-\bigcirc-$ Vehicle (intraperitoneal $n=7$, days 20-23)

Figure 3 Late treatment (days 20 to 23 ).

Notes: Withdrawal thresholds of cuff-implanted rats were measured to determine the effect of repeated progesterone treatment starting 20 days after model induction. Rats were given progesterone $4 \mathrm{mg} / \mathrm{kg}$ intraperitoneally (closed circles; $\mathrm{n}=6$ ) or peanut oil vehicle (open circles; $n=7$ ) for four days starting on day 20 after cuff implantation. No differences in hind paw withdrawal thresholds were observed over the 103-day observation period. Arrow denotes time of cuff implantation, and shaded area indicates days on which injections were given. Data are expressed as means \pm standard error of the mean.

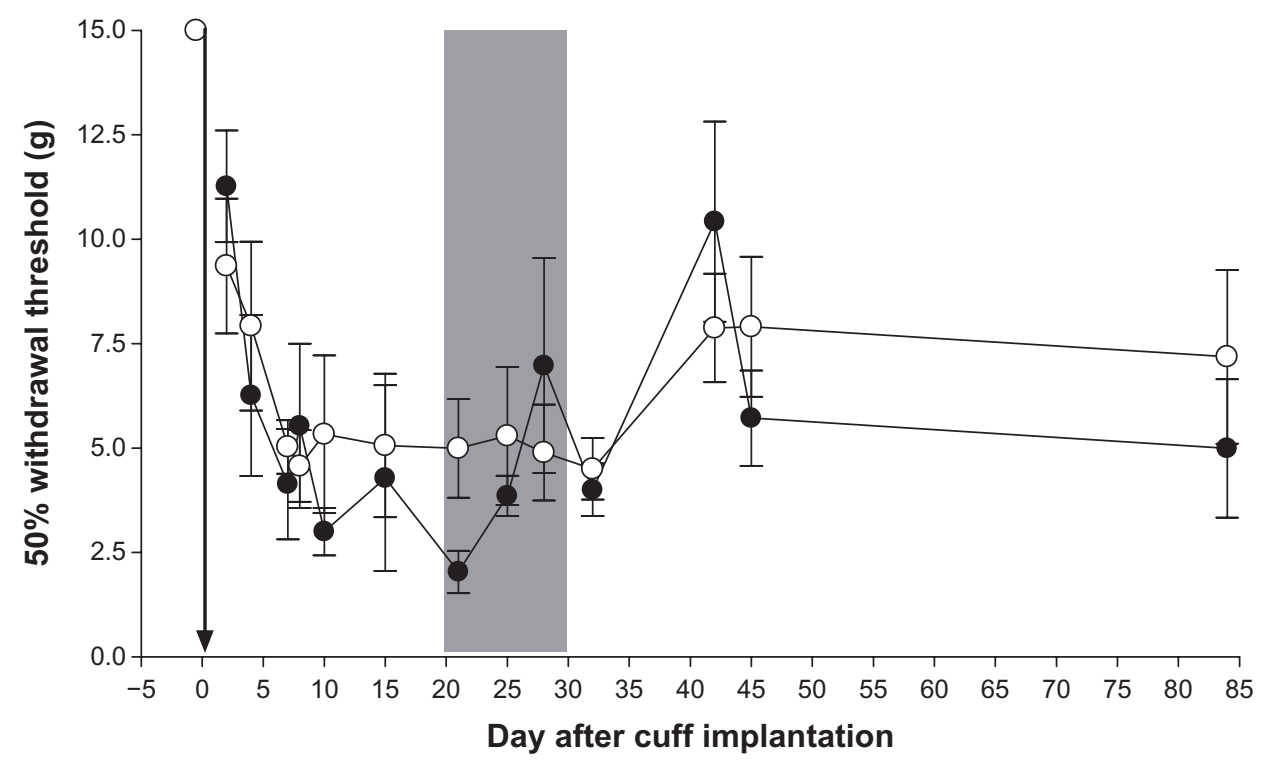

Progesterone (4 mg/kg, i.p., $\mathrm{n}=6$, treatment on days 20-30)

- Vehicle (i.p., $\mathrm{n}=7$, days 20-30)

Figure 4 Late treatment (days 20 to 30 ).

Notes: Withdrawal thresholds of cuff-implanted rats were measured to determine the effect of repeated progesterone treatment starting 20 days after model induction. Rats were given repeated progesterone $4 \mathrm{mg} / \mathrm{kg}$ intraperitoneally (closed circles; $\mathrm{n}=6$ ) or peanut oil vehicle (open circles; $\mathrm{n}=7$ ) starting on day 20 after cuff implantation and continued daily until day 30. No differences in hind paw pain withdrawal thresholds were observed over the 84-day observation period. Arrow denotes time of cuff implantation, and shaded area indicates days on which injections were given. 
of variance was used for single-dose progesterone testing (Figures 5 and 6). The Bonferroni test was used for post hoc comparisons, and all analyses were performed using Prism 4.03 (GraphPad Software, Inc, San Diego, CA).

\section{Results}

\section{Early treatment: Daily progesterone administration starting one hour after surgery}

Prior to cuff implantation, all rats showed baseline withdrawal thresholds of approximately $15 \mathrm{~g}$. One hour after cuff implantation surgery, rats were given progesterone $4 \mathrm{mg} / \mathrm{kg}$ or peanut oil vehicle intraperitoneally. Progesterone or vehicle injections were continued daily for the next four days (PROG d0-4, VEH d0-4, Figure 1) or 10 days (PROG d0-10, VEH d0-10, Figure 2). Figure 1 illustrates the decrease in withdrawal thresholds after cuff implantation for both PROG d0 - 4 and VEH d0 - 4, but the decrease was more gradual in the progesterone-treated group. Both groups reached their lowest values by day 10 . Thereafter, there was a gradual increase in withdrawal thresholds in both groups, which leveled off by approximately day 35 . Although the thresholds for the PROG d0-4 group were usually numerically higher than VEH d0-4, there was no statistically significant effect of treatment $[\mathrm{F}(1,99)=4.72, P=0.053]$. Figure 2 illustrates the changes in withdrawal thresholds after cuff implantation and treatment for the groups PROG d0-10 and VEH d0-10. The main effect of treatment was significant $[\mathrm{F}(1,156)=14.62$, $P=0.0021]$. Post hoc comparisons showed that the PROG d0-10 group had significantly higher withdrawal thresholds compared with VEH d0-10 on days 30, 35, and 40, and on the final day of testing, day 85 (all $P$ values $<0.05$ ). Data were analyzed with a repeated measures two-way analysis of variance using the Bonferroni post hoc test.

\section{Late treatment: Daily progesterone administration starting 20 days after surgery}

Prior to cuff implantation, all rats showed baseline withdrawal thresholds of approximately $15 \mathrm{~g}$. Following cuff implantation, withdrawal thresholds decreased to approximately $5 \mathrm{~g}$ by day 6 in both groups (Figures 3 and 4). Figure 3 illustrates the withdrawal thresholds of rats given injections for four days starting on day 20, PROG d20-23 and VEH d20-23. Thresholds were at approximately $5 \mathrm{~g}$ in both groups when injections were started. No differences in thresholds were observed between rats given the progesterone and the vehicle [the main effect of treatment was not significant, $[\mathrm{F}(1,143)=0.003, P=0.96]$. Figure 4 shows the withdrawal thresholds of rats given injections for a total of 11 days starting on day 20, PROG d20-30 and VEH d20-30. There were no differences between the two groups on any of the days tested over the 84-day observation period (the main effect of treatment was not significant, $[\mathrm{F}(1,132)=0.24, P=0.63])$. Data were analyzed with a repeated measures two-way analysis of variance with the Bonferroni post hoc test.

\section{Single-dose effect of progesterone}

There were no changes in withdrawal thresholds at 30,60, or 90 minutes after single-dose progesterone administration

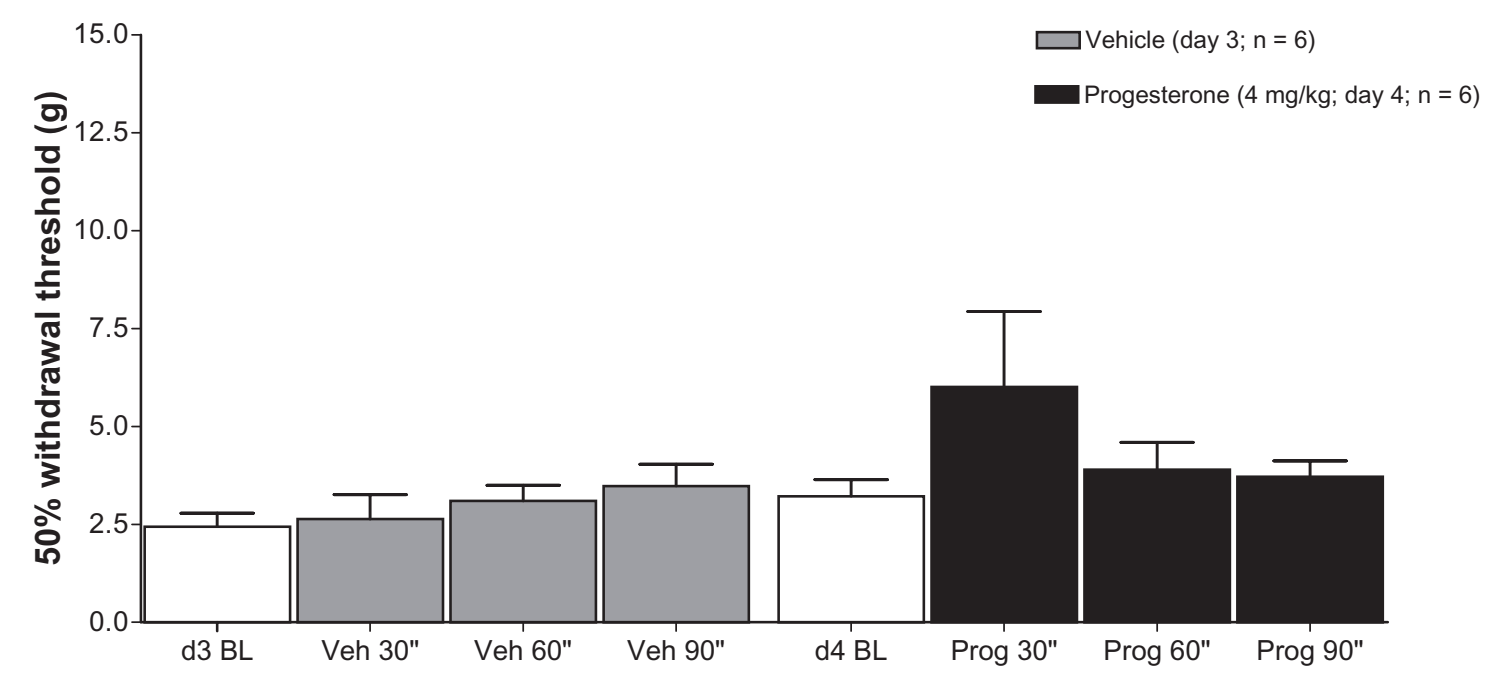

Figures 5 Single-dose treatment.

Notes: Single-dose progesterone $4 \mathrm{mg} / \mathrm{kg}$, intraperitoneally (black columns; $\mathrm{n}=6$ ) or peanut oil vehicle (grey columns; $\mathrm{n}=6$ ) did $\mathrm{not}$ have an effect on paw withdrawal thresholds, as measured at 30,60 , and 90 minutes after injection. Data are expressed as means \pm standard error of the mean. 


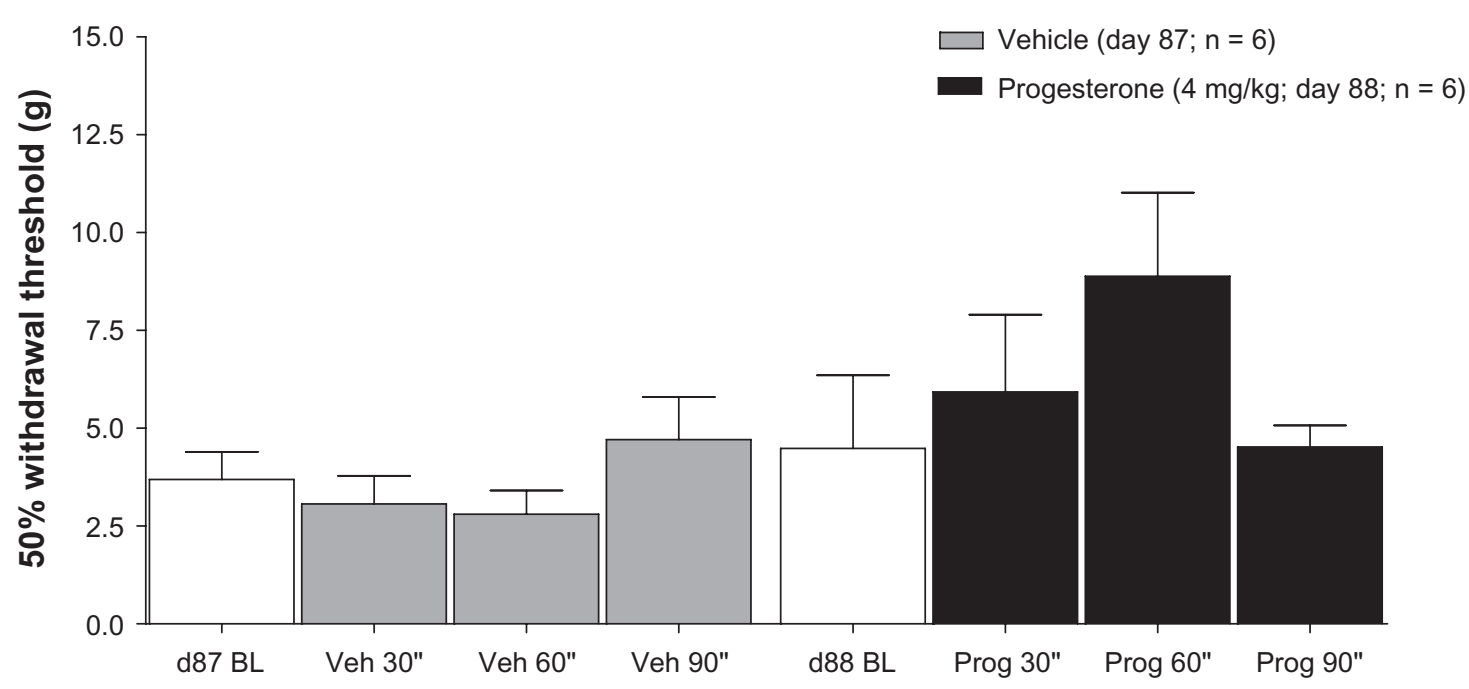

Figure 6 Single-dose treatment.

Notes: Single-dose progesterone $4 \mathrm{mg} / \mathrm{kg}$, intraperitoneally (black columns; $\mathrm{n}=6$ ) or peanut oil vehicle (grey columns; $\mathrm{n}=6$ ) did not have an effect on paw withdrawal thresholds, as measured at 30,60, and 90 minutes after injection. Data are expressed as means \pm standard error of the mean.

(4 mg/kg, intraperitoneally) compared with baseline, when tested on day $4[\mathrm{~F}(3)=1.26, P=0.32]$ or day $88[\mathrm{~F}(3)=1.4$, $P=0.27]$ after cuff implantation. Vehicle administration was also without effect at 30,60 , or 90 minutes after injection, when given on day $3[\mathrm{~F}(3)=1.65, P=0.22]$ or day 87 $[\mathrm{F}(3)=2.05, P=0.15]$. Results are shown in Figures 5 and 6. Data were analyzed with a repeated measures one-way analysis of variance using the Bonferroni post hoc test.

\section{Discussion}

The aim of the present study was to determine if progesterone administration in a rat model of peripheral neuropathic pain would delay or limit the development of tactile hypersensitivity (termed "allodynia" in humans ${ }^{33}$ ) in a rat model of neuropathic pain. Repeated progesterone treatment that started immediately (one hour) after model induction, and continued for four days, did not have a significant effect on the development of tactile hypersensitivity over a 12-week observation period. However, when progesterone was started immediately after model induction, and continued for 10 days, there was a recovery of tactile hypersensitivity in the later part of the study, after treatment had ended. Repeated progesterone administration (for 4 or 11 days) starting late after model induction, ie, on day 20, when hypersensitivity was already established, did not have an effect. Also, a single injection of progesterone did not have an effect on hypersensitivity within 90 minutes of administration when given on day 4 or on day 88 after model induction. In summary, progesterone promoted the recovery of this model of peripheral neuropathic pain, when given as repeated injections during the early phase of model development and for a sufficient period of time.

Progesterone is synthesized by neurons and glial cells of the central and peripheral nervous systems, and has been reviewed elsewhere. ${ }^{34-36}$ Progesterone, like all steroid hormones, is derived from cholesterol. Cholesterol is converted to progesterone via the intermediate, pregnenolone. Progesterone is metabolized in neurons to $5 \alpha$-dihydroprogesterone which can activate the progestin receptor. $5 \alpha$-dihydroprogesterone is converted in a reversible manner by the enzyme $3 \alpha$-hydroxysteroid oxidoreductase ( $3 \alpha$-HSOR) to $3 \alpha, 5 \alpha$ tetrahydroprogesterone (allopregnanolone) which is a positive allosteric modulator of the $\mathrm{GABA}_{\mathrm{A}}$ receptor. Classical intracellular progestin receptors have been localized to several regions of the brain, spinal cord, and peripheral neurons. ${ }^{34}$ Other targets of progesterone have been identified, ie, the sigma 1 receptor, ${ }^{37}$ the nicotinic acetylcholine receptor, ${ }^{38}$ and a family of putative membrane receptors that have been cloned. ${ }^{39}$ It is thought that the diversity of progesterone targets is responsible for its pleiotropic effects, which include neuroprotection, neuroregeneration, and remyelination. ${ }^{22}$

Presently there is extensive evidence that progesterone and its metabolites have neuroprotective effects in models of peripheral neuropathy. In the streptozotocin-induced model of diabetes in the rat, treatment with progesterone and $5 \alpha$-dihydroprogesterone for one month reduced myelin infolding in the sciatic nerve. ${ }^{40}$ Chronic treatment with progesterone or its derivatives reversed impairments in nerve conduction velocity, nociception, skin innervation density, and $\mathrm{Na}^{+}, \mathrm{K}^{+}$-ATPase activity, and also increased mRNA levels 
of myelin proteins. ${ }^{41}$ Sameni et $\mathrm{al}^{42}$ showed similar results in the same model, in that chronic treatment with progesterone improved conduction velocity, edema, axon diameter, thickness of myelin, and abnormalities in fiber infolding and myelin compaction in the sciatic nerve. Progesterone, $5 \alpha$-dihydroprogesterone, and $3 \alpha, 5 \alpha$-tetrahydroprogesterone reversed many of the changes seen in the aging rat nervous system, such as decreased expression of glycoprotein zero and peripheral myelin protein $22,{ }^{43}$ decreased numbers of thin myelinated fibers, as well as myelin infolding and irregularities in shape. ${ }^{44,45}$ In a study of guided nerve regeneration, chitosan prostheses containing progesterone and pregnenolone improved nerve generation in the rabbit facial nerve. ${ }^{46}$ Repeated treatment with the progestin receptor antagonist, mifepristone, starting on postnatal day 1 caused a decrease in axon diameter and increased neurofilament density. ${ }^{47}$ Following nerve crush injury, progesterone and $5 \alpha$-dihydroprogesterone treatment increased thermal nociceptive thresholds, and restored alterations in myelin proteins and in the $\mathrm{Na}^{+}, \mathrm{K}^{+}$-ATPase pump induced by the injury. ${ }^{32}$ It is noteworthy that these results were found with treatment that was initiated early (starting one day after surgery) and given repeatedly, similar to the protocol used in the present study.

Beyond its putative role in neuroprotection, other studies have reported analgesic or antinociceptive properties. For example, recent studies have highlighted a role for progesterone and its metabolites in peripheral neuropathic pain. Meyer et $\mathrm{al}^{48}$ found an upregulation of $3 \alpha$-HSOR in the spinal cord of rats with sciatic nerve injury caused by four loose ligatures. $3 \alpha, 5 \alpha$-tetrahydroprogesterone administered intrathecally into the spinal cord increased thermal and mechanical thresholds. Medroxyprogesterone acetate, an antagonist of $3 \alpha, 5 \alpha$-tetrahydroprogesterone, had the opposite effect. In a rat model of chemotherapy-induced neuropathic pain, progesterone, $5 \alpha$-dihydroprogesterone, and $3 \alpha, 5 \alpha$-tetrahydroprogesterone prevented and reversed vincristine-induced mechanical allodynia and thermal hyperalgesia, as well as a number of nerve irregularities. ${ }^{49}$ Also, in a vincristine-induced model of neuropathy, long-term administration of the anxiolytics, etifoxine, increased the rate of recovery. ${ }^{50}$ Prophylactic administration of etifoxine abolished development of neuropathic pain. This effect was inhibited by medroxyprogesterone acetate, suggesting the effect was due to $3 \alpha$-neurosteroids. In a spinal cord injury model of neuropathic pain, daily progesterone administration for approximately one month reversed mechanical and cold allodynia. ${ }^{51}$ The authors found that this was correlated with an attenuation of the $N$-methyl-D-aspartate receptor and protein kinase $\mathrm{C}$ gamma upregulation, and an increased expression of the kappa opioid receptor. This suggests an effect of progesterone on key components of the nociceptive pathway in the spinal cord.

Conflicting results regarding the effects of progesterone in nerve injury models have been observed. It has been shown that female rats show higher pain sensitivity than males following L5 nerve root ligation. ${ }^{52}$ Using hormone replacements in ovarectomized rats, it was determined that progesterone was responsible for this hypersensitivity. ${ }^{53}$ The authors suggested that one of the possible explanations for this finding is that a physiological dose of progesterone was used, while other studies reporting antinocieptive effects used supraphysiological doses. In a mouse model of spinal nerve ligation, antagonism of the progestin receptor and inhibition of the transport protein, peripheral benzodiazepine receptor, increased mechanical and thermal thresholds. ${ }^{54-56} 3 \alpha, 5 \alpha$-tetrahydroprogesterone decreased the antinociceptive effect of the peripheral benzodiazepine receptor antagonist, suggesting the effect of the latter was partly due to decreasing the activity of the $\mathrm{GABA}_{\mathrm{A}}$ receptor. Species differences may account for the discrepancies in results. Also, the acute effect of test compounds was determined 2-3 weeks after model induction, which may involve additional mechanisms.

Beneficial effects of progesterone on acute and tonic models of nociception have also been reported. Acute administration of progesterone or a peripheral benzodiazepine receptor agonist (4-chlordiazepam) decreased nociceptive scores in the tail flick test and the formalin test. The effects of both drugs were reversed by bicuculline in the tail flick test only. ${ }^{57}$ In a separate study, progesterone and metabolites active at the $\mathrm{GABA}_{\mathrm{A}}$ receptor increased tail flick latencies. ${ }^{58}$ In the formalin test, progesterone decreased pain scores during the first phase. ${ }^{59}$ Also in the formalin test, $\mathrm{GABA}_{\mathrm{A}}$ receptor active metabolites of progesterone decreased nociceptive scores in the second phase of the test. ${ }^{60} 3 \alpha, 5 \alpha-$ tetrahydroprogesterone increased nociceptive thresholds to thermal and mechanical stimuli in naïve and carageenaninjected rats, likely through positive allosteric modulation of the $\mathrm{GABA}_{\mathrm{A}}$ receptor. ${ }^{61}$

Given the multitude of central and peripheral effects that have been attributed to progesterone and/or its derivatives, it is not surprising that a number of mechanisms of action have been proposed. Progesterone and its 
derivatives may have neuroprotective, anti-inflammatory, and/or antinociceptive effects. ${ }^{62,63}$ Progesterone and $5 \alpha$ dihydroprogesterone can act through the classical progestin receptor to cause an upregulation of glycoprotein zero, a protein important for the structural integrity of the myelin sheath. $3 \alpha, 5 \alpha$-tetrahydroprogesterone acting as a positive allosteric modulator of the $\mathrm{GABA}_{\mathrm{A}}$ receptor through a genomic mechanism can cause an upregulation of peripheral myelin protein 22 which is also critical for myelination. ${ }^{64}$ Progesterone may directly stimulate the proliferation of Schwann cells by acting on receptors expressed in these cells. These positive effects on remyelination may account for recovery of neuronal function in models of peripheral neuropathy.

Further investigation is required in order to draw any conclusions regarding progesterone's mechanism(s) of action in the present study. Given that progesterone did not have a single-dose effect, it may be interpreted that progesterone was not acting as an analgesic, and by extrapolation, the effect of early repeated administration does not appear to be due to an analgesic effect. Because progesterone promotes recovery of tactile hypersensitivity with long-term treatment during the early phase of model development, it may be postulated that progesterone or its active metabolites may be having a neuroprotective effect in this model. Remyelination may be a plausible cause of recovery, because neuronal degeneration is a component of peripheral neuropathy. ${ }^{28}$

The implication of the present study and previous work is that progesterone may be an effective therapy for chronic neuropathic pain. In this study, progesterone was effective only when started immediately after nerve injury and given for a sufficient period of time, suggesting that the timing and duration of treatment are both critical for the effect. That progesterone alters the development of the model when given early, but not late, suggests that there is a window of opportunity for treatment. It is well known that treatment of traumatic brain injury, spinal cord injury, and stroke must be started immediately, and the same may hold true for peripheral nerve injuries and insults. Many people with neuropathic pain go for months or even years after injury or onset of the disease before being given a correct diagnosis and/or treatment. Therefore, it is not surprising that, in many cases, their neuropathic pain is refractory to treatment. Beginning an effective regimen of therapy at the earliest possible time, and maintaining treatment for a sufficient period, may be critical in altering the course of this condition. Therefore, early progesterone treatment may prevent the development of a chronic unrelenting course of neuropathic pain.

\section{Acknowledgments}

This work was supported by a grant from McMaster University. We are grateful to Dr Henry Szechtman for inspiring this project and his initial discussions and ongoing advice.

\section{Disclosure}

The authors report no conflicts of interest in this work.

\section{References}

1. Kehlet H, Jensen TS, Woolf CJ. Persistent postsurgical pain: Risk factors and prevention. Lancet. 2006;367(9522):1618-1625.

2. Bordet T, Pruss RM. Targeting neuroprotection as an alternative approach to preventing and treating neuropathic pain. Neurotherapeutics. 2009;6(4):648-662.

3. Gilron I, Watson CP, Cahill CM, Moulin DE. Neuropathic pain: A practical guide for the clinician. CMAJ. 2006;175(3):265-275.

4. Boureau F, Doubrere JF, Luu M. Study of verbal description in neuropathic pain. Pain. 1990;42(2):145-152.

5. McDermott A, Toelle T, Rowbotham D, Schaefer C, Dukes E. The burden of neuropathic pain: Results from a cross-sectional survey. Eur J Pain. 2006;10(2):127-135.

6. Berger A. Clinical characteristics and economic costs of patients with painful neuropathic disorders. J Pain. 2004;5(3):143-149.

7. Attella MJ, Nattinville A, Stein DG. Hormonal state affects recovery from frontal cortex lesions in adult female rats. Behav Neural Biol. 1987;48(3):352-367.

8. Roof RL, Duvdevani R, Stein DG. Gender influences outcome of brain injury: Progesterone plays a protective role. Brain Res. 1993;607(1-2): 333-336.

9. Roof RL, Duvdevani R, Heyburn JW, Stein DG. Progesterone rapidly decreases brain edema: Treatment delayed up to 24 hours is still effective. Exp Neurol. 1996;138(2):246-251.

10. Roof RL, Duvdevani R, Braswell L, Stein DG. Progesterone facilitates cognitive recovery and reduces secondary neuronal loss caused by cortical contusion injury in male rats. Exp Neurol. 1994;129(1): 64-69.

11. Jiang N, Chopp M, Stein D, Feit H. Progesterone is neuroprotective after transient middle cerebral artery occlusion in male rats. Brain Res. 1996;735(1):101-107.

12. Jiang C, Wang J, Li X, Liu C, Chen N, Hao Y. Progesterone exerts neuroprotective effects by inhibiting inflammatory response after stroke. Inflamm Res. 2009;58(9):619-624.

13. Kumon Y, Kim SC, Tompkins P, Stevens A, Sakaki S, Loftus CM Neuroprotective effect of postischemic administration of progesterone in spontaneously hypertensive rats with focal cerebral ischemia J Neurosurg. 2000;92(5):848-852.

14. Cai W, Zhu Y, Furuya K, Li Z, Sokabe M, Chen L. Two different molecular mechanisms underlying progesterone neuroprotection against ischemic brain damage. Neuropharmacology. 2008;55(2): $127-138$.

15. Ishrat T, Sayeed I, AtifF, Stein DG. Effects of progesterone administration on infarct volume and functional deficits following permanent focal cerebral ischemia in rats. Brain Res. 2009;1257:94-101.

16. Wang J, Jiang C, Liu C, Li X, Chen N, Hao Y. Neuroprotective effects of progesterone following stroke in aged rats. Behav Brain Res. 2010; 209(1):119-122.

17. Ogata T, Nakamura Y, Tsuji K, Shibata T, Kataoka K. Steroid hormones protect spinal cord neurons from glutamate toxicity. Neuroscience. 1993;55(2):445-449.

18. Labombarda F, Gonzalez SL, Gonzalez DM, Guennoun R, Schumacher M, de Nicola AF. Cellular basis for progesterone neuroprotection in the injured spinal cord. J Neurotrauma. 2002;19(3):343-355. 
19. Gonzalez Deniselle MC, Lopez-Costa JJ, Saavedra JP, et al. Progesterone neuroprotection in the Wobbler mouse, a genetic model of spinal cord motor neuron disease. Neurobiol Dis. 2002;11(3):457-468.

20. El-Etr M, Vukusic S, Gignoux L, et al. Steroid hormones in multiple sclerosis. J Neurol Sci. 2005;233(1-2):49-54.

21. Stein DG, Wright DW, Kellermann AL. Does progesterone have neuroprotective properties? Ann Emerg Med. 2008;51(2):164-172.

22. Schumacher M, Guennoun R, Stein DG, De Nicola AF. Progesterone: Therapeutic opportunities for neuroprotection and myelin repair. Pharmacol Ther. 2007;116(1):77-106.

23. Wright DW, Kellermann AL, Hertzberg VS, et al. ProTECT: A randomized clinical trial of progesterone for acute traumatic brain injury. Ann Emerg Med. 2007;49(4):391-402.

24. Xiao G, Wei J, Yan W, Wang W, Lu Z. Improved outcomes from the administration of progesterone for patients with acute severe traumatic brain injury: A randomized controlled trial. Crit Care. 2008;12(2):R61.

25. Stein DG, Wright DW. Progesterone in the clinical treatment of acute traumatic brain injury. Expert Opin Investig Drugs. 2010;19(17):847-857.

26. Confavreux C, Hutchinson M, Hours MM, Cortinovis-Tourniaire P, Moreau T. Rate of pregnancy-related relapse in multiple sclerosis. Pregnancy in Multiple Sclerosis Group. New Engl J Med 1998;339(5): 285-291.

27. Vukusic S, Hutchinson M, Hours M, et al. Pregnancy and multiple sclerosis (the PRIMS study): Clinical predictors of post-partum relapse. Brain. 2004;127(Pt 6):1353-1360.

28. Mosconi T, Kruger L. Fixed-diameter polyethylene cuffs applied to the rat sciatic nerve induce a painful neuropathy: Ultrastructural morphometric analysis of axonal alterations. Pain. 1996;64(1):37-57.

29. Chaplan SR, Bach FW, Pogrel JW, Chung JM, Yaksh TL. Quantitative assessment of tactile allodynia in the rat paw. J Neurosci Methods. 1994;53(1):55-63

30. Pitcher GM, Ritchie J, Henry JL. Paw withdrawal threshold in the von Frey hair test is influenced by the surface on which the rat stands. J Neurosci Methods. 1999;87(2):185-193.

31. Gonzalez Deniselle MC, Lopez-Costa JJ, Saavedra JP, et al. Progesterone neuroprotection in the Wobbler mouse, a genetic model of spinal cord motor neuron disease. Neurobiol Dis. 2002;11(3): 457-468.

32. Roglio I, Bianchi R, Gotti S, et al. Neuroprotective effects of dihydroprogesterone and progesterone in an experimental model of nerve crush injury. Neuroscience. 2008;155(3):673-685.

33. Merskey H, Bogduk N. Classification of Chronic Pain. Volume 2. Seattle, WA: IASP Press; 1994.

34. Schumacher M, Guennoun R, Robert F, et al. Local synthesis and dual actions of progesterone in the nervous system: Neuroprotection and myelination. Growth Horm IGF Res. 2004;14 Suppl A:S18-S33.

35. Patte-Mensah C, Kibaly C, Boudard D, et al. Neurogenic pain and steroid synthesis in the spinal cord. $J$ Mol Neurosci. 2006;28(1): $17-31$.

36. Mensah-Nyagan AG, Do-Rego JL, Beaujean D, Luu-The V, Pelletier G, Vaudry H. Neurosteroids: Expression of steroidogenic enzymes and regulation of steroid biosynthesis in the central nervous system. Pharmacol Rev. 1999;51(1):63-81.

37. Su TP, London ED, Jaffe JH. Steroid binding at sigma receptors suggests a link between endocrine, nervous, and immune systems. Science. 1988;240(4849):219-221.

38. Valera S, Ballivet M, Bertrand D. Progesterone modulates a neuronal nicotinic acetylcholine receptor. Proc Natl Acad Sci U SA. 1992;89(20): 9949-9953.

39. Zhu Y, Bond J, Thomas P. Identification, classification, and partial characterization of genes in humans and other vertebrates homologous to a fish membrane progestin receptor. Proc Natl Acad Sci U SA. 2003; 100(5):2237-2242.

40. Veiga S, Leonelli E, Beelke M, Garcia-Segura LM, Melcangi RC. Neuroactive steroids prevent peripheral myelin alterations induced by diabetes. Neurosci Lett. 2006;402(1-2):150-153.
41. Leonelli E, Bianchi R, Cavaletti G, et al. Progesterone and its derivatives are neuroprotective agents in experimental diabetic neuropathy: A multimodal analysis. Neuroscience. 2007;144(4):1293-1304.

42. Sameni HR, Panahi M, Sarkaki A, Saki GH, Makvandi M. The neuroprotective effects of progesterone on experimental diabetic neuropathy in rats. PakJ Biol Sci. 2008;11(16):1994-2000.

43. Melcangi RC, Magnaghi V, Galbiati M, Ghelarducci B, Sebastiani L, Martini L. The action of steroid hormones on peripheral myelin proteins: A possible new tool for the rebuilding of myelin? J Neurocytol. 2000;29(5-6):327-339.

44. Melcangi RC, Azcoitia I, Ballabio M, et al. Neuroactive steroids influence peripheral myelination: A promising opportunity for preventing or treating age-dependent dysfunctions of peripheral nerves. Prog Neurobiol. 2003;71(1):57-66.

45. Azcoitia I, Leonelli E, Magnaghi V, Veiga S, Garcia-Segura LM, Melcangi RC. Progesterone and its derivatives dihydroprogesterone and tetrahydroprogesterone reduce myelin fiber morphological abnormalities and myelin fiber loss in the sciatic nerve of aged rats. Neurobiol Aging. 2003;24(6):853-860.

46. Chavez-Delgado ME, Gomez-Pinedo U, Feria-Velasco A, et al. Ultrastructural analysis of guided nerve regeneration using progesteroneand pregnenolone-loaded chitosan prostheses. J Biomed Mater Res. 2005;74(1):589-600.

47. Melcangi RC, Leonelli E, Magnaghi V, Gherardi G, Nobbio L, SchenoneA. Mifepristone (RU 38486) influences expression of glycoprotein Po and morphological parameters at the level of rat sciatic nerve: In vivo observations. Exp Neurol. 2003;184(2):930-938.

48. Meyer L, Venard C, Schaeffer V, Patte-Mensah C, Mensah-Nyagan AG. The biological activity of 3alpha-hydroxysteroid oxido-reductase in the spinal cord regulates thermal and mechanical pain thresholds after sciatic nerve injury. Neurobiol Dis. 2008;30(1):30-41.

49. Meyer L, Patte-Mensah C, Taleb O, Mensah-Nyagan AG. Cellular and functional evidence for a protective action of neurosteroids against vincristine chemotherapy-induced painful neuropathy. Cell Mol Life Sci. 2010;67(17):3017-3034.

50. Aouad M, Charlet A, Rodeau J-L, Poisbeau P. Reduction and prevention of vincristine-induced neuropathic pain symptoms by the non-benzodiazepine anxiolytic etifoxine are mediated by $3 \alpha$-reduced neurosteroids. Pain. 2009;147(1-3):54-59.

51. Coronel MF, Labombarda F, Villar MJ, De Nicola AF, González SL. Progesterone prevents allodynia after experimental spinal cord injury. J Pain. 2011;12(1):71-83.

52. LaCroix-Fralish ML, Tawfik VL, DeLeo JA. The organizational and activational effects of sex hormones on tactile and thermal hypersensitivity following lumbar nerve root injury in male and female rats. Pain. 2005;114(1-2):71-80.

53. Lacroix-Fralish M, Tawfik V, Nutilemcmenemy N, Deleo J. Progesterone mediates gonadal hormone differences in tactile and thermal hypersensitivity following L5 nerve root ligation in female rats. Neuroscience. 2006;138(2):601-608.

54. Kondo D, Saegusa H, Yabe R, et al. Peripheral-type benzodiazepine receptor antagonist is effective in relieving neuropathic pain in mice. J Pharmacol Sci. 2009;110(1):55-63.

55. Belelli D, Lambert JJ. Neurosteroids: Endogenous regulators of the GABAA receptor. Nat Rev Neurosci. 2005;6(7):565-575.

56. Kondo D, Yabe R, Kurihara T, Saegusa H, Zong S, Tanabe T. Progesterone receptor antagonist is effective in relieving neuropathic pain. Eur J Pharmacol. 2006;541(1-2):44-48.

57. Gambhir M, Mediratta PK, Sharma KK. Evaluation of the analgesic effect of neurosteroids and their possible mechanism of action. Ind $J$ Physiol Pharmacol. 2002;46(2):202-208.

58. Frye CA, Duncan JE. Progesterone metabolites, effective at the GABAA receptor complex, attenuate pain sensitivity in rats. Brain Res. 1994;643(1-2):194-203.

59. Kuba T, Wu HB, Nazarian A, et al. Estradiol and progesterone differentially regulate formalin-induced nociception in ovariectomized female rats. Horm Behav. 2006;49(4):441-449. 
60. Ocvirk R, Pearson Murphy BE, Franklin KB, Abbott FV. Antinociceptive profile of ring A-reduced progesterone metabolites in the formalin test. Pain. 2008;138(2):402-409.

61. Charlet A, Lasbennes F, Darbon P, Poisbeau P. Fast non-genomic effects of progesterone-derived neurosteroids on nociceptive thresholds and pain symptoms. Pain. 2008;139(3):603-609.

62. Leonelli E, Ballabio M, Consoli A, Roglio I, Magnaghi V, Melcangi RC. Neuroactive steroids: A therapeutic approach to maintain peripheral nerve integrity during neurodegenerative events. $J$ Mol Neurosci. 2006;28(1):65-76.
63. Melcangi RC, Garcia-Segura LM. Therapeutic approaches to peripheral neuropathy based on neuroactive steroids. Expert Rev Neurother. 2006;6(8):1121-1125.

64. Lambert JJ, Cooper MA, Simmons RD, Weir CJ, Belelli D. Neurosteroids: Endogenous allosteric modulators of GABA(A) receptors. Psychoneuroendocrinology. 2009;34 Suppl 1:S48-S58.

\section{Publish your work in this journal}

The Journal of Pain Research is an international, peer-reviewed, open access, online journal that welcomes laboratory and clinical findings in the fields of pain research and the prevention and management of pain. Original research, reviews, symposium reports, hypothesis formation and commentaries are all considered for publication.

\section{Dovepress}

The manuscript management system is completely online and includes a very quick and fair peer-review system, which is all easy to use. Visit http://www.dovepress.com/testimonials.php to read real quotes from published authors. 